\title{
Era uma vez... um estudo de caso sobre histórias e estórias adotivas
}

\author{
Once upon a time... A case study on \\ adoption history and stories
}

\author{
Larissa Cristina Silveira de ANDRADE \\ Martha Franco Diniz HUEB ${ }^{2}$ \\ Carolina Martins Pereira ALVES
}

\begin{abstract}
Resumo
Trata-se de pesquisa-intervenção, ancorada por estudo de caso instrumental, que objetivou verificar os efeitos da narrativa de histórias na elaboração de angústias da adoção de criança maior, bem como mediar a inserção na família adotiva. Participaram do estudo a mãe e o pai adotivos e um garoto de seis anos. Para a coleta de dados foram utilizadas entrevistas semiestruturadas com os adotantes, enquanto com a criança se submeteu o Procedimento Desenho-Estória e sessões de narração de histórias infantis com a temática adotiva. Os resultados revelaram a importância dos contos para viabilizar reflexões e elaborações sobre o processo de adoção, assim como para auxiliar o contato com angústias primitivas e facilitar a inserção na nova família. A despeito do amparo proporcionado à criança através da narração das histórias, identificou-se a necessidade de fornecer suporte psicológico ao grupo familiar, a fim de solidificar a construção dos vínculos afetivos.
\end{abstract}

Palavras-chave: Adoção; Criança; Narração de estórias; Psicanálise.

\begin{abstract}
An intervention research based on an instrumental case study aimed at verifying the effects of storytelling on the anxiety resulting from the adoption of an older child and at assessing the child integration into the foster family. The adoptive mother and father of a six-year-old boy participated in this study. Data were collected through semi-structured interviews conducted with the adoptive parents. The story-drawing procedure and children's storytelling sessions sharing stories about adoption were used with the child. The results revealed the importance of stories to promote reflections and elaborations on the adoption process, help the contact with primitive anxieties, and facilitate the integration into the new family. Although the use of storytelling provides support to the child, we identified the need to provide psychological support to the family in order to foster the establishment of affective ties.
\end{abstract}

Keywords: Adoption; Child; Storytelling; Psychoanalysis.

\footnotetext{
1 Universidade Federal do Triângulo Mineiro, Curso de Psicologia, Grupo de Estudos e Pesquisa em Psicanálise. Av. Getúlio Guaritá, 159, 38025-440, Uberaba, MG, Brasil. Correspondência para/Correspondence to: L.C.S. ANDRADE. E-mail: <andrade.larissa@hotmail.com>.

2 Universidade Federal do Triângulo Mineiro, Departamento de Psicologia, Grupo de Estudos e Pesquisa em Psicanálise. Uberaba, MG, Brasil.
} 
A partir da promulgação da Lei $n^{\circ} 12.010$, também conhecida como a "Nova Lei da Adoção", observam-se no cenário brasileiro importantes alterações na concepção e construção do processo de filiação adotiva, o que permite uma inovadora visão sobre o tema. Em vigor desde agosto de 2009, destaca-se como questão central a prioridade dada à criança, principalmente quando se trata do tempo despendido pelo Judiciário na decisão acerca da reinserção na família de origem ou extensa e, em último caso, da disponibilização para adoção. Segundo essa lei, a destituição do convívio familiar e a inserção em programas de adoção devem ser decididas pelo Judiciário dentro de no máximo dois anos (Brasil, 2009), o que diminui consideravelmente a permanência da criança na instituição, favorecendo o crescimento afetivo no seio de uma nova família.

A possibilidade de reconstrução da concepção de família proporcionada pela nova lei promoveu o desenvolvimento de uma cultura da adoção. Se antes era vista de maneira preconceituosa, encoberta por medos, silêncios e mitos do senso comum (Vargas, 1998), atualmente a mídia aponta que a população está superando os preconceitos. Os brasileiros estão aceitando adotar crianças maiores de dois anos ou de diferentes raças, além daquelas com necessidades especiais, as quais antes estavam fadadas a crescer em situação de acolhimento. Em decorrência das alterações nas configurações familiares e da possibilidade de pensar sobre uma nova cultura instituída, o processo adotivo hoje se dá por múltiplas formas e contextos, ou seja, mesmo se observando que a maior demanda parte de jovens casais com problemas de infertilidade, o desejo pela adoção é manifestado também por casais com filhos biológicos, casais na meia idade, casais homoafetivos e pessoas solteiras. Dessa forma, a adoção não tem sido mais vista como a última opção de casais que não podem gerar seus filhos biológicos, mas sim como outra possibilidade de constituição familiar, podendo resultar em vivências satisfatórias tanto para os pais quanto para as crianças (Schettini, Amazonas, \& Dias, 2006).

Em geral os processos de filiação por adoção

174 não apresentam distinções entre si, mas existem alguns que requerem atenção especializada e cuidado por parte daqueles que se propõem a acompanhá-los. Tais processos apresentam uma menor demanda, como a adoção de irmãos e de portadores de doenças físicas e mentais, assim como a adoção inter-racial e a de crianças acima de dois anos de idade, hoje preferencialmente nomeada de adoção de crianças maiores (Ferreira \& Carvalho, 2000; Peiter, 2011).

Tendo em perspectiva o sofrimento da criança mais velha que foi institucionalizada após perder o convívio familiar, é importante ressaltar que, ao se desvincular de quem Ihe prestava os cuidados, mesmo que insuficientes ou inadequados, e sob o cuidado de diferentes pessoas e instituições, há uma descontinuidade na linha da vida, que pode levar ao prejuízo do desenvolvimento adequado da personalidade (Hueb, 2002). Sabendo que as primeiras vivências da criança são de extrema importância para a formação de seu psiquismo, pode-se inferir que a privação de cuidados e afetos adequados tende a acarretar sérias dificuldades afetivas, inclusive instabilidade emocional. Nesse sentido, Peiter (2011) faz uma interessante associação entre os encontros e despedidas na adoção de crianças maiores.

Diferentes braços acolheram, ou não acolheram a criança, que pode ter experimentado sucessivas vezes a árdua tarefa de ligar-se e desligar-se de pessoas a sua volta. Falamos então de um percurso de vínculos e rompimentos, que podem ter ocorrido sem um necessário processo elaborativo trazendo consequências na formação de novos vínculos (p.51).

Portanto, ressalta-se que o prolongamento estabelecido entre as vivências de separação da mãe biológica e o amparo pela família adotiva pode acarretar marcas no desenvolvimento da personalidade e dificultar o estabelecimento das relações objetais, desencadeando o sentimento de desamparo na criança (Levinzon, 2008). Essas separações abruptas, em geral, são vivenciadas por intensos desconfortos, os quais Winnicott (1963/1983) denominou de angústias imagináveis ou de angústias de aniquilamento. 
Levizon (2008) afirma que a angústia de separação e a sensação de aniquilamento representam a questão central do psiquismo do adotado, e que a complexidade dessa angústia, associada à díade vinculação e abandono, pode se sobressair em tais crianças. Isso se deve ao fato de a dependência do objeto de amor ser sentida como ameaçadora, uma vez que o medo de um novo abandono faz com que elas continuamente entrem em contato com vivências anteriores de aniquilamento, para a citada autora. Entretanto, o desenvolvimento de um bom contato com o adotante pode ajudar a criança maior a se sentir compreendida e contida, podendo suprir, "pelo menos em parte, as rupturas no desenvolvimento e as condições adversas que dificultam a formação de um ego bem estruturado" (Levinzon, 2008, p.44).

Partindo da premissa de que todo encontro é também despedida, deduz-se que toda despedida pode vir a ser um novo encontro (Peiter, 2011), a depender do investimento afetivo dos envolvidos. Nesse sentido, para que se processe um vínculo gratificante entre adotante e adotado é importante que a criança reviva suas separações para poder dirigir-lhes novos significados. Logo, o objetivo deste trabalho vai ao encontro da necessidade de ressignificação da nova filiação, propondo verificar os efeitos da narrativa de histórias infantis na elaboração das angústias da criança maior e ser mediadora da inserção na família adotiva.

\section{Método}

Participaram deste estudo uma criança de seis anos, Nicolas, e seus pais adotivos, Carlos e Joana. Trata-se de um recorte de uma pesquisainterventiva mais ampla, desenvolvida com seis crianças, adotadas após os dois anos de idade. Optou-se pelo estudo de caso instrumental (Stake, 2000), de uma criança dentre as seis pesquisadas, por se tratar do único caso de guarda provisória concretizado um mês antes do início da coleta de dados, fato que possibilitou acompanhar mais proximamente o desenvolver da inserção familiar, diferentemente das outras cinco crianças, que haviam sido adotadas há mais de quatro anos. Os pais adoti- vos foram informados dos procedimentos que seriam realizados e assinaram o Termo de Consentimento Livre e Esclarecido (TCLE), assim como autorizaram a participação da criança. Esta também foi informada sobre os encontros e o assunto a ser abordado, e consentiu verbalmente em participar. A pesquisa foi aprovada pelo Comitê de Ética em Pesquisa da Universidade Federal do Triângulo Mineiro, por meio do Parecer n 2251/2012.

\section{Instrumentos}

Para a coleta de dados foram utilizados três instrumentos norteadores, a saber: Entrevistas semiestruturadas com o casal adotante; Procedimento Desenho-Estória Com Tema (DE-T); e Narração de histórias infantis com a criança.

\section{Procedimentos}

O estudo foi dividido em três fases. Na primeira delas entrevistaram-se os pais com o propósito de investigar sobre a história de vida do filho e de como estavam vivenciando o processo adotivo. Nessa mesma fase realizou-se o primeiro DE-T com a criança, tendo como tema "Desenhe a sua família" e conforme orientado por Trinca (1997), solicitou-se que contasse uma estória a respeito do que havia desenhado e que lhe desse um título.

Na segunda fase, durante cinco semanas, tendo como suporte cinco livros infantis com a temática adotiva, narraram-se histórias para o participante. Após a leitura dos livros "A estrelinha distraída" (Souza, 2010), "Adotar uma estrela" (Mostacchi, 1995), "Uma dose de amor" (Souto, 1997), "O dia em que eu fiquei sabendo" (Bel, 2004) e "O filho por adoção" (Weber, 2004), o garoto era estimulado a conversar livremente sobre os conteúdos apresentados e relacioná-los com suas vivências atuais, finalizando com a produção de trabalhos artísticos, como desenhos e colagens que recontavam ou ilustravam cada história.

Na terceira e última fase, os adotantes foram novamente entrevistados a fim de verificar se houve percepção de mudanças significativas no relacionamento paterno-filial. Com a criança, realizou-se o 
segundo DE-T com a mesma temática do primeiro, "Desenhe a sua família". Manteve-se a mesma instrução, com a finalidade de compará-lo com o primeiro DE-T e verificar se houve alterações após as intervenções com a narração das histórias citadas.

As entrevistas semiestruturadas e os comentários pós narração de histórias foram analisados segundo o Processo Compreensivo, que consiste em dar um sentido e reconhecer o que é relevante e significativo para o participante (Trinca, 1984), enquanto o DE-T foi analisado segundo o referencial de Tardivo (2011).

\section{Breve história sobre Nicolas}

Ao iniciar a pesquisa, Nicolas, então com seis anos de idade, e seu irmão, que acabara de completar dois anos, se encontravam em processo de guarda provisória. As crianças haviam sido acolhidas pelo casal Carlos e Joana, com idade média de 55 anos, no mês anterior ao início da coleta de dados do estudo. Destaca-se que o garoto mais novo não participou da pesquisa por não se inserir no critério de adoção de criança maior. Antes de Nicolas vir a conviver com o casal adotante, havia residido por quatro anos de forma intermitente em uma Instituição de Acolhimento em uma cidade do interior de Minas Gerais. Nessa época foram realizadas algumas tentativas de reintegração em sua família biológica e família extensa, sem êxito. Em suas idas e vindas durante a institucionalização, o menino presenciou vários conflitos entre seus pais biológicos. Durante o período que permaneceu na Instituição, Nicolas vivenciou algumas tentativas frustradas de adoção, sendo devolvido em uma delas; porém seu processo de filiação só se iniciou com a família atual. A criança chegou ao Centro de Estudo e Pesquisa em Psicologia Aplicada (CEPPA) por intermédio dos pais adotivos, com a queixa de que ele apresentava dificuldade em adaptar-se à nova casa e à nova cidade, apresentando sintomas de enurese e terror noturno.

\section{Resultados e Discussão}

Segundo o casal adotivo, o local onde Ni176 colas estava institucionalizado era uma cidade próxi- ma ao município da residência familiar e, dessa forma, eles se hospedaram em um hotel por uma semana para conhecer as crianças e conviver com elas, assim como para organizar a documentação necessária à adoção. Ao se encontrarem pela primeira vez, dentro da Instituição, os meninos demonstraram estar ansiosos, porém foram receptivos e logo ficaram à vontade com os visitantes. Após o primeiro contato, mantiveram encontros diários dentro e fora da instituição de acolhida, para que pudessem estabelecer o início de um bom vínculo durante a fase de convivência e transição que os preparasse para a mudança de cidade e moradia e para a constituição de uma nova família.

Ao final da semana o casal retornou com os novos filhos para a cidade de origem, optando por viajar ao entardecer. Nicolas adormeceu durante o percurso e só despertou ao chegar à nova casa, por volta das 21 horas. Ao acordar a noite sem reconhecer o local onde estava, o menino, muito assustado, entrou em pânico e começou a chorar, o que denota que as mudanças de cidade, de cuidadores e de moradia fizeram desencadear o reviver de vários abandonos e rompimentos afetivos ao longo da curta, mas sofrida história de vida. Segundo Silva (2009), é importante a elaboração de um segundo luto ao se desvincular dos laços afetivos estabelecidos na Instituição. Nesse sentido, o contato com o novo desencadeou em Nicolas defesas ligadas ao medo de um possível abandono em relação à nova família (Levinzon, 2009), uma vez que outros tantos se registravam em sua memória.

Após a mudança, os pais relataram dificuldade da criança em dormir, pesadelos frequentes e enurese noturna, a qual não se dava na instituição de acolhimento. Demonstraram muita preocupação e dúvidas sobre como lidar com a reação do menino, o que não difere da literatura. Ferreira (2003, p.50), focando as relações entre adotantes e adotado, afirma que "todos os envolvidos direta ou indiretamente nessa chegada da criança passam a viver um processo de adaptação, de ajustamento a uma novíssima situação". Diante da preocupação dos novos pais, destaca-se a importância de compreender a adoção como um processo, no qual as relações 
vão se estreitando aos poucos, conforme a convivência, pois "necessita de tempo, compreensão e amor para que possa existir" (Silva, 2009, p.58).

Os sentimentos angustiantes vivenciados por Nicolas e relatados pelo casal adotivo podem ser mais bem compreendidos a partir do primeiro DE-T realizado pela criança, que conseguiu expressar sua dificuldade em conciliar os diferentes acontecimentos de sua vida (Figura 1).

A produção contém várias informações e ambiguidades, as quais demonstram seus sentimentos derivados do conflito "abandono versus novo vínculo". A partir da representação simultânea do sol e da lua, do arco-íris e da chuva, aqui compreendidos como símbolos da claridade e da escuridão, a criança reforçou o que havia contado no início do desenho: "eu não sei desenhar coisas difíceis". Quando questionado sobre o que seria um desenho difícil, informou: "desenhar coisa que eu não dou conta", ou seja, não conseguia expressar as mazelas da vida, o que é de difícil compreensão para uma criança tão jovem e com uma história de muito sofrimento.

Nicolas relatou, através de palavras e da produção do DE-T, sua dificuldade em compreender seu histórico de abandono, mostrando claramente os sentimentos que o invadiam: o de angústias impensáveis, para as quais não têm definição. Segundo Silva (2009), o reviver das perdas dos laços afetivos de uma criança adotada mais velha, demanda cuidados especiais para que esta consiga elaborar vivências anteriores, de forma a não acarretar reflexos negativos na constituição dos novos vínculos. Ao dizer que não dá conta de desenhar coisas difíceis, Nicolas anuncia sua necessidade de cuidado em relação às mudanças que ocorreram ao ingressar na nova família.

Devido às sensações de difícil definição e à descontinuidade dos vínculos primários em suas

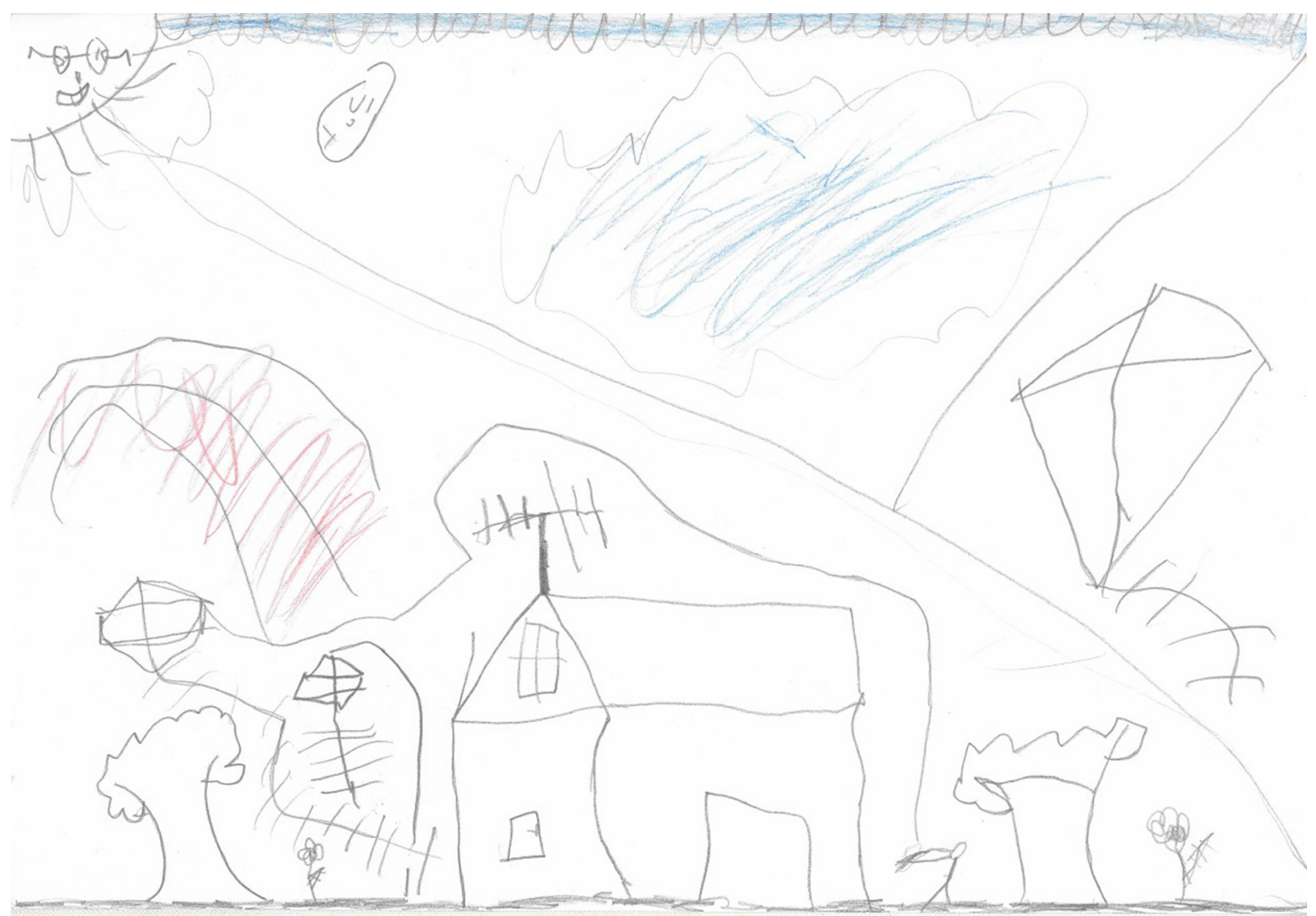


vivências, ao desenhar o primeiro DE-T, apesar da solicitação "Desenhe sua família", a criança não a representou. Desenhou apenas a si próprio, bem pequeno e com uma casa ao lado, como pode ser observado na Figura 1. Em relação a si, demonstrou necessidade e preocupação em ser aceito, pedindo por vezes à investigadora que guardasse segredo sobre os acontecimentos de sua vida, o que foi compreendido como forma de evitar que todo passado de sofrimento, assim como sentimentos ambivalentes em relação aos pais, não os incomodassem, o que supostamente poderia causar outro abandono. De forma semelhante ao relatado por Briani (2008), ao desenhar sua imagem, Nicolas buscava a construção de si como sujeito diferenciado, mas trazendo consigo os reflexos das falhas básicas que o acompanhavam, como demonstrado por sua figura sozinha, segurando um fio de pipa cortado, sem vínculo.

Segundo Briani (2008, p.52), é possível captar "na transferência que há sentimentos e fantasias pré-verbais tão primitivas que escapam à expressão da linguagem, precisando ser revividas, reconstruídas e colocadas em palavras, com a ajuda do terapeuta". Ao possibilitar que Nicolas recordasse as diferentes vivências pelas quais passou, a pesquisadora-terapeuta o ajudou a reconstruir e experienciar sensações inquietantes para que assim, posteriormente, iniciasse o processo de elaboração dos acontecimentos.

Recordar o anteriormente vivenciado e vislumbrar a possibilidade de um futuro diferente ocasionaram sensações que transbordaram, deixando-o permanecer no escuro, assim como contou sobre o primeiro DE-T, em que a lua era "rudiada" por São Jorge. A confusão de pensamentos, que se apresentavam em grandes proporções, fez a criança dizer que o desenho não tinha estória, que a parte escura era indefinida. Infere-se que tais manifestações de angústia engendradas ao seu redor são despertadas por reavivarem os sentimentos relativos às separações. Por vezes a criança sente que não pode conter dentro de si sentimentos que vêm acompanhados pela fantasia de perda (Briani, 178 2008).

\section{(Re) construindo a história...}

"Obrigada estrelinha distraída, graças às suas confusões somos papai, mamãe e filhinha" (Souza, 2010, p.5), repetiu Nicolas ao iniciarmos a primeira das cinco histórias infantis sobre a adoção. Ao entrar em contato com os livros infantis, demonstrou bastante atenção em relação aos acontecimentos e vivências dos personagens de cada história, apresentando diferentes reações no decorrer da narração. Durante as cinco semanas que se seguiram, nas demais leituras, expressou aos poucos sua familiaridade com o assunto, podendo compartilhar estórias e histórias sobre o tema.

O apropriar-se das vivências dos personagens narrados nos encontros proporcionou-lhe o contato com suas próprias angústias inquietantes. Segundo Bettelheim (1980), os contos possibilitam, de maneira suave, que as crianças tenham certo controle sobre seus dramas internos e busquem soluções para seus dilemas. Seguindo a mesma linha de pensamento, Rosa (2008) acrescenta que os benefícios não se restringem aos contos de fadas; inclusive afirma que toda e qualquer história utilizada para o reconhecimento de fantasias é útil por permitir a colocação das angústias em palavras. Aponta ainda que "as histórias infantis sempre tiveram o poder de auxiliar as crianças a nomear e suportar seus conflitos básicos" (p.99).

Nesse sentido, pode-se associar a importância dos contos infantis ao pensamento lacaniano. "O fato de que o sujeito revive e rememora os eventos formadores da sua existência no sentido intuitivo da palavra, não é em si mesmo, tão importante. O que conta é o que ele disso reconstrói", diz Lacan (1953/1986, p.22). Dessa forma depreende-se que Nicolas pôde então reconstruir e reviver experiências em relação à adoção, a partir do contato com as narrações.

Ao reviver sua história, reorganizou-se ao expressar angústias, das quais a mais evidente parece ter sido a da sua estada na Instituição de Acolhimento, associada a outras tentativas frustradas de adoção. Conversando sobre a estória da estrelinha distraída, aquela que entregou uma criança por engano para outro casal (Souza, 2010), expôs que 
não se pode entregar um filho para outra pessoa: "Porque se não... se não... o filho que deu pra outra pessoa vai para a Casa Lar. Vai para a adoção. Ai depois vai pra outra família, aí depois vai para a Casa Lar e aí depois vai para outras famílias". Tantas vezes assim? Perguntou a pesquisadora. "Anham. Já fez isso comigo, me adotou toda hora, todo, todo, todo dia que eu tava na Casa Lar".

Essa expressão deixa claro como todo o processo de institucionalização foi angustiante e incompreensível para ele, com as idas e vindas durante o período de acolhimento: tentativa sem êxito de recolocá-lo em sua família biológica e, posteriormente, tentativas frustrantes de adoção.

Segundo Peiter (2011, p.50), "reviver circunstâncias de dependência absoluta ou de desamparo nos assusta, levando-nos a angústias e medos conhecidos e desconhecidos, mesmo que não lembrados conscientemente". Nesse sentido, os encontros e despedidas presenciados expuseram a criança a novas descontinuidades de vínculos, fazendo-a reviver medos primitivos e a angústia de separação.

Esse sentimento angustiante se fez presente também em seu relato sobre os dias em que permaneceu na Instituição à espera de uma família, os quais puderam ser colocados em palavras quando Nicolas relatou sua experiência de adoção:

Quando você é adotado, nois vai pra..., nois fica sessenta dias, sessenta mil, sessenta dias, nossa... . Duzentos dias sem sê adotado. Ai em sessenta, no final de sessenta já de noite, já de noite que nois tem que ir embora, de dia não dá.

Para a criança, os quatro anos institucionalizados foram visceralmente sentidos e experienciados como intermináveis sessenta mil dias à espera de uma família que o acolhesse como filho. E quando finalmente os dias se passaram e a viagem para sua nova casa ocorreu à noite, viu-se imerso em sentimentos ambivalentes, dentre eles o medo do novo. Seria um bom lugar, uma boa família, ou seria novamente devolvido?

Apesar das angústias do novo contidas nas expressões do menino, é possível perceber em outro recorte de sua fala a vontade de se afastar do que ele até então conhecia como família: "Eu ficava triste, não gosto que ninguém briga, por isso que eu não quero essa família mais, porque eles briga muito. A minha família biológica".

Ao final das cinco semanas de narrações, Nicolas, ainda demonstrando a confusão de sentimentos, conseguiu expressar simbolicamente o processo pelo qual estava passando. Ao término do último livro (Weber, 2004), criou espontaneamente o que nomeou de "uma novela" à qual intitulou Guerra de Amor. Em voz alta, pôs-se a dizer:

Já faz amor. Em um dia, no coração, quando não se é adotado o coração é todo preto, mas quando vem uma família..., no primeiro dia que a família chega prá adotá... . Ainda nois não somo adotado, quando nois ainda tá no abrigo [fala bem baixinho]. Quando, eu fui adotado no abrigo, aí quando as pessoa da família chegou meu coração ficou vermelhinho e branco. E essa parte aqui, desses peito aqui, uma parte ficou um pouco preta. Então... aí ficou de outro jeito, ficou com cor de ouro.

Com a voz trêmula, baixa e fala aparentemente confusa, e sem muita estruturação lógica de começo, meio e fim, conseguiu poeticamente expressar a inquietude de sua vida em uma novela - novela nomeada como sendo uma guerra: brigas físicas entre os pais biológicos e brigas internas da própria criança, mas que permanece com esperança pelo amor. É através do simbolismo do coração antes preto, depois vermelhinho e em seguida cor de ouro, que ele revive sua história: pulsante com a chegada dos novos pais, marcado pelos acontecimentos e vínculos desfeitos, porém, esperançoso para se tornar cor de ouro, precioso para alguém.

O resgate da história afetiva e social de Nicolas através das intervenções pareceu-nos ter-lhe dado novos contornos psíquicos às vivências emocionais dissociadas. Esse fato é também compartilhado por Góis (2005), que assegura que o benefício da construção narrativa da adoção, por intermédio do terapeuta, possibilita a reconstrução de histórias e identidades dos adotados a partir da compreensão de sua origem. Dentro da mesma linha, 
Gutfreind (2003, p.111) afirma que "narrar pode ser, enfim, melhorar".

\section{A possibilidade de uma nova família}

Após cinco semanas reconstruindo e revivendo as histórias de Nicolas, realizou-se um segundo DE-T de modo a avaliar os efeitos da narração de histórias no relacionamento entre adotado e adotantes. Como no primeiro, pediu-se: "Desenhe a sua família" (Figura 2).

Ao iniciar sua produção, a criança disse que não desenharia "todas as suas famílias", optando por representar apenas a atual. Demonstrou que tem recordações antigas, mas que sua escolha está direcionada à família que o acolheu na adoção. Após expressar sua vontade, o menino anunciou seus sentimentos em relação à nova família. Ficou evidente que o vínculo entre eles estava sendo construído aos poucos, com a convivência, o amor e o cuidado. Ao desenhar o que lhe era solicitado, ia comentando que inicialmente da terra revolvida brotaria o capim, e depois as árvores e as flores.
Nesse sentido, Ferreira (2003, p.13) acrescenta que "a disponibilidade, o amor, a lucidez e o empreendimento dos pais no cuidar da criança adotada tardiamente potencializam o convívio". Simbolicamente, a criança expressou através do segundo DE-T o cuidado parental, expressando a existência de um solo fértil, o qual permitiu iniciar o estabelecimento de vínculos com a nova família (o germinar de árvores e flores). A imagem representada de sua família nesta última produção contém três pessoas, diferentemente da primeira em que somente retratava a si. Identificou os personagens como sendo a mãe, ele e o pai, todos com os braços bem abertos. Ao terminar as três figuras, ele afirmou ser dessa maneira que conseguia desenhar os pais, de braços bem abertos, demonstrando estar acolhido e amparado pelo carinho dos dois.

Entretanto, observou-se que a construção do vínculo em sua nova família era permeada por vivências anteriores bastante angustiantes, devido à ambivalência de sentimentos em relação aos membros que a compõem, fato que ainda desenca-

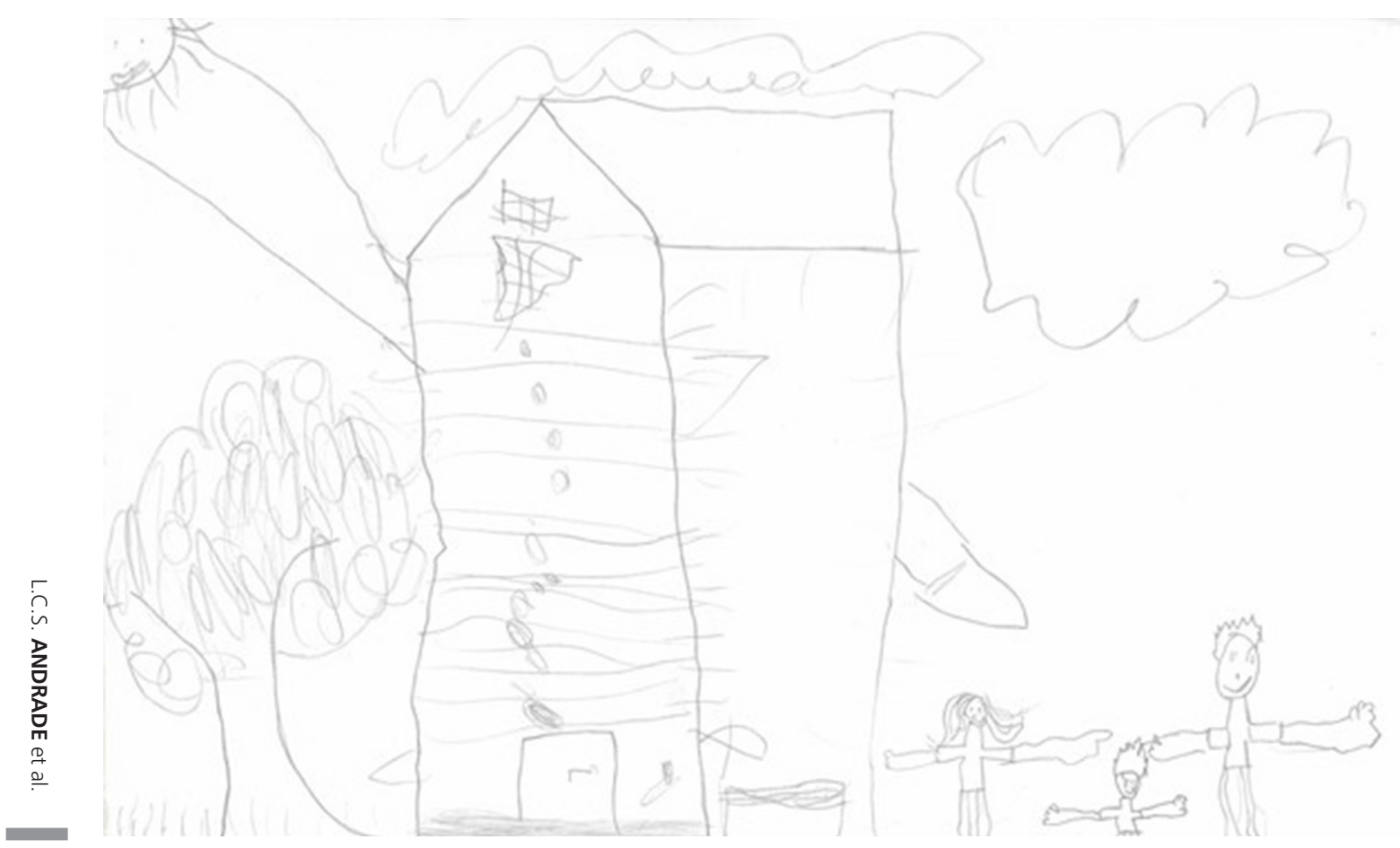


deava nele sentimentos persecutórios. Ao contar, com a expressão feliz, que seu pai adotivo iria comprar uma pipa, relembrou que aprendeu a confeccioná-la na sua cidade natal com o pai biológico, porém logo pediu segredo, demonstrando receio de que a informação pudesse magoar o pai adotivo. Tanto os acontecimentos alegres quanto os sofridos na antiga família deveriam ser mantidos em segredo, segundo a vontade de Nicolas.

Sua necessidade em relembrar tornou-se muito presente ao final da pesquisa-intervenção. Por diversas vezes retomou as brigas e situações de violência que presenciou ao lado dos pais biológicos. Repetia compulsivamente os fatos, como que tentando elaborar as cenas que o marcaram, deixando transparecer seu medo de vincular-se com a nova família e sofrer outro abandono. Ao vivenciar e verbalizar medos terroríficos, reafirmava a necessidade de cuidado. Na estória do segundo DE-T, a casa desenhada era na verdade um hospital, no qual, segundo ele, deveria permanecer internado porque se encontrava doente. Simbolicamente, o hospital desenhado parece representar o cuidado que os novos pais estavam proporcionando, cuidado esse necessário para cicatrizar feridas originárias de vivências angustiantes de antigos vínculos desfeitos.

Esse cuidado necessário para cicatrização das feridas de Nicolas pôde ser presenciado no discurso de seus pais adotivos, na segunda entrevista sobre o processo interventivo. Os pais enfatizaram o dia em que a família compartilhou a experiência de conversar sobre a adoção, a partir da iniciativa de Nicolas, ao levar para casa um dos livros infantis trabalhados (Souza, 2010) no segundo encontro. Ilustra-se com o relato de Carlos, o qual foi seguido de expressão de concordância de Joana, balançando afirmativamente a cabeça enquanto o esposo descrevia:

Naquele momento do livrinho, da questão da adoção, ele tava tendo muito atrito na escola com a professora. Desrespeitando a professora, agredindo, agredindo os colegas, jogando o sapato e tava "barra mesmo" com a questão da professora. Aí um belo dia ele me traz a questão do livrinho e eu aproveitei a deixa e falei pra ele: olha a questão da adoção, Nicolas, não é eu, o papai e a mamãe que vamos te adotar, mas você também está nos adotando. E você, além de estar nos adotando, você precisa adotar a professora, você precisa adotar a escola, adotar a cidade, olha, a cidade também está te adotando, então você também tem que adotar a cidade.

Através do desejo da criança e da abertura dos pais para conversar sobre o processo adotivo, viabilizaram reviver experiências angustiantes, possibilitando que a criança sentisse pertencer à família e ao ambiente que o cerca. Conforme Menegotto (2006), a filiação é resultante de uma inscrição simbólica, que pode ser compreendida pelo sentimento de reconhecimento e pertencimento da criança no seu contexto familiar e social. Ao proporcionarem a oportunidade de Nicolas expressar seus sentimentos, os pais adotivos possibilitaram o início da inscrição da criança em sua família.

Assim como a criança pôde expressar durante a pesquisa-intervenção, os pais adotivos também enfatizaram a natureza progressiva do vínculo de filiação. Carlos, em especial, relatou que:

É um tempo emocional. Eu também fico assim, pensando. A gente precisa de um tempo, mas é um tempo, é um tempo pra nós quatro, pra nós quatro aprendermos, é um tempo de estabilizar, de estabelecer. Hoje já existe um diálogo entre nós, um acordo melhor, até minha relação com a Joana está melhor, mas é um tempo emocional que vai depender, é uma média entre os quatro.

O vínculo é estabelecido gradativamente, necessitando tempo, compreensão e amor para se constituir. O afeto necessita de proximidade tanto física quanto emocional, devendo ser conquistado na convivência (Badinter, 1985). Nesse sentido, ressalta-se a necessidade de os pais adotivos atarem os laços do passado com o presente, para que a criança seja introduzida em sua rede familiar, tornando-a agente de sua própria história (D'Andrea, 2002), possibilitando que os vínculos se deem de maneira gradual, através de um aprendizado, como todas as relações (Penteado, 2012). É através do estabelecimento do que os pais nomearam de tempo emocional que há possibilidade de reconhe- 
cimento e intimidade construídos no dia a dia, cultivados por um solo fértil que poderá germinar e dar frutos.

\section{Considerações Finais}

Compreendendo, com fundamento em Góis (2005), que "é a vida que passa a ser orquestrada a partir de novas, diferentes e estranhas sinfonias, as quais irão se harmonizar segundo a criação de outros significados e registros de ação no e para o mundo" (p.117), depreende-se que a nova e diferente sinfonia que estava em processo na história de Nicolas ocasionou sentimentos ambivalentes, retomando vivências mais primitivas, como a angústia de aniquilamento. No entanto, observa-se que a narração de histórias com personagens adotados propiciaram o início da compreensão do significado da adoção e da inserção na nova família.

Recriando outros significados de sua história de vida através das histórias infantis, o garoto pôde refletir e iniciar o processo de elaboração de vivências que marcaram seus primeiros vínculos. Contudo, angústias arcaicas relacionadas ao medo do abandono e a ambiguidade de sentimentos frente à nova constituição familiar, ainda se fazem presentes no imaginário da criança, mesmo que tenha sido iniciado o processo de inserção familiar.

Apesar dos benefícios proporcionados pelas histórias, observa-se que tanto a criança quanto os pais adotantes desta pesquisa-intervenção necessitam de acompanhamento psicológico ao longo da constituição do vínculo familiar. Foi oferecida a continuidade de atendimento psicológico aos familiares, o qual foi prontamente aceito; tanto o casal quanto as crianças seguem em psicoterapia no CEPPA.

Destaca-se que o estudo não esgota o tema, e nem pode ser generalizado, pois tratou da intervenção de um único caso, mas parece ter sido suficiente para sugerir que equipes psicossociais que trabalham com crianças institucionalizadas e adoções poderiam se aliar a outros dispositivos de saúde mental, de forma a serem facilitadores da transição desse processo entre os envolvidos. No contexto da nova cultura da adoção, instituído na última década, destaca-se a atuação dos Grupos de Apoio a Adoções que, além de prestar informações jurídicas, têm a importante função de indiretamente dar suporte emocional, ao promover entre seus membros o compartilhamento de experiências, possibilitando estreitar mais e mais os laços dessa importante filiação.

\section{Colaboradores}

Todos os autores contribuíram na concepção e desenho do estudo, análise de dados e redação final.

\section{Referências}

Badinter, E. (1985). Um amor conquistado: o mito do amor materno. Rio de Janeiro: Nova Fronteira.

Bel, L. (2004). O dia em que eu fiquei sabendo. São Paulo: Salamandra.

Bettelheim, B. (1980). A psicanálise dos contos de fadas. Rio de Janeiro: Paz e Terra.

Brasil. (2009). Presidência da República. Lei no 12.010, de 3 de agosto de 2009. Nova lei nacional da adoção. Recuperado em agosto 6, 2013, de http://www. planalto.gov.br/ccivil_03/_Ato2007-2010/2009/Lei/ L12010.htm

Briani, A. C. T. (2008). A subjetividade na adoção: um pequeno ensaio. Contemporânea: Psicanálise e Transdisciplinaridade, 6, 36-54. Recuperado em janeiro 18, 2014, de http://www.revistacontemporanea.org.br/ site/wp-content/artigos/artigo187.pdf

D'Andrea, A. (2002). O casal adotante. In M. Andolfi (Org.), A crise do casal: uma perspectiva sistêmicorelacional (pp.233-247). Porto Alegre: Artmed.

Ferreira, M. P., \& Carvalho, S. R. (2000). $1^{\circ}$ Guia de adoção de crianças e adolescentes do Brasil. Novos caminhos, dificuldades e possiveis soluções. São Paulo: Winners.

Ferreira, R. P. (2003). Adoção tardia e adaptação à vida em família na perspectiva dos pais (Dissertação de mestrado não-publicada). Universidade Católica de Pernambuco.

Góis, C. A. (2005). O estranho e o fantástico: uma intervenção terapêutica em um caso de adoção. Revista Brasileira de Crescimento e Desenvolvimento Humano, 15(2), 111-118.

Gutfreind, C. (2003). O terapeuta e o lobo: a utilização do conto na psicoterapia da criança. São Paulo: Casa do Psicólogo.

Hueb, M. F. D. (2002). Privação materna e adoção tardia: ferida na alma ou travessia compartilhada (Dissertação 
de mestrado não-publicada). Pontifícia Universidade Católica de São Paulo.

Lacan, J. (1986). O seminário, livro 1: os escritos técnicos de Freud. Rio de Janeiro: Jorge Zahar. (Originalmente publicado em 1953).

Levinzon, G. K. (2008). A criança adotiva na clínica psicanalítica ( $2^{a}$ ed.). São Paulo: Escuta.

Levinzon, G. K. (2009). Adoção. Clínica psicanalítica (3a ed.). São Paulo: Casa do Psicólogo.

Menegotto, L. M. O. (2006). Da filiação à inclusão: uma articulação entre psicanálise e educação. In E. P. G. Moura (Org.), Educação, cultura e trabalho. Novo Hamburgo: Feevale.

Mostacchi, M. (1995). Adotar uma estrela. São Paulo: Paulus.

Peiter, C. (2011). Adoção: vínculos e rupturas: do abrigo à familia adotiva. São Paulo: Zagodoni.

Penteado, P. A. (2012). Construção social da maternidade. Revista Brasileira de Terapia Familiar, 4(1), 23-34. Recuperado em fevereiro 28, 2014, de http://www. abratef.org.br/2014/Revista-vol4/RevistaAbratef-V4pag-23-34.pdf

Rosa, D. B. (2008). A narratividade da experiência adotiva: fantasias que envolvem a adoção. Psicologia Clínica, 20(1), 97-110. Recuperado em fevereiro 12, 2013, de http://www.scielo.br/pdf/pc/v20n1/07.pdf

Schettini, S. S. M., Amazonas, M. C. L. A., \& Dias, C. M. S. B. (2006). Famílias adotivas: identidade e diferença. Psicologia em Estudo, 11(2), 285-293. Recuperado em fevereiro 12, 2013 de http://www.scielo.br/pdf/pe/ v11n2/v11n2a06.pdf

Silva, J. A. (2009). Adoção de crianças maiores: percepções e vivências dos adotados (Dissertação de mestrado não-publicada). Pontifícia Universidade Católica de Minas Gerais. Recuperado em fevereiro
12, 2013, de http://www1.pucminas.br/documentos/ dissertacao_jaqueline_araujo.pdf

Souto, M. A. G. (1997). Uma dose de amor. São Paulo: Edicon.

Souza, H. P. (2010). A estrelinha distraída: adoção para crianças. Curitiba: Juruá.

Stake, R. E. (2000). Case studies. In N. K. Denzin \& Y. S. Lincoln (Orgs.), Handbook of qualitative research (pp.435-454). London: Sage.

Tardivo, L. S. L. P. C. (2011). O procedimento de DesenhosEstórias (D-E) e seus derivados: fundamentação teórica, aplicações em clínica e pesquisa. In A. E. Villemor-Amaral \& B. S. G. Werlang (Orgs.), Atualizações em métodos projetivos para avaliação psicológica (pp.435-454). São Paulo: Casa do Psicólogo.

Trinca, A. M. T. (1997). Avaliação e expansão. In W. Trinca (Org.), Formas de investigações clínica em psicologia: procedimento de desenhos-estória (pp.35-66). São Paulo: Vetor.

Trinca, W. (1984). Processo diagnóstico de tipo compreensivo. In W. Trinca (Org.), Diagnóstico psicológico: a prática clínica (pp.14-24). São Paulo: EPU.

Vargas, M. M. (1998). Adoção tardia: da família sonhada à família possível. São Paulo: Casa do Psicólogo.

Weber, L. N. D. (2004). O filho por adoção: um manual para crianças. Paraná: Juruá.

Winnicott, D. W. (1983). Da dependência à independência no desenvolvimento do indivíduo. In D. W. Winnicott (Org.), O ambiente e os processos de maturação: estudos sobre a teoria do desenvolvimento emocional. Porto Alegre: Artes Médicas. (Originalmente publicado em 1963).

Recebido: janeiro 27, 2014

Versão final: março 24, 2015

Aprovado: junho 30, 2015 
